\title{
A Comparative Evaluation of Nitroglycerine and Esmolol in Attenuating the Haemodynamic Response to Laryngoscopy and Intubation
}

\author{
Arun Kumar Saxena', Ravneet Kaur ${ }^{2}$, B L Mathur ${ }^{3}$, A P Verma ${ }^{4}$ \\ ${ }^{1}$ Assistant Professor, Department of Anaesthesia JNU Medical College Jaipur, ${ }^{2}$ Senior Resident, Department of Anaesthesia JNU Medical College Jaipur, \\ ${ }^{3}$ Professor and Head, Department of Anaesthesia JNU Medical College Jaipur, ${ }^{4}$ Professor, Department of Anaesthesia JNU Medical College Jaipur.
}

\section{Abstract}

Background: Laryngoscopy and tracheal intubation provoke stress response manifesting as hypertension and tachycardia. There is urgent need for drug which can attenuate the cardiovascular response to the laryngoscopy and intubation. Subjects and Methods: The study was conducted in department of anaesthesia in JNUIMSRC. 50 Patients belonging to ASA grade 1 and 2 posted for surgery under general anaesthesia were randomly divided into two groups of 25 each. Premedication with Midazolam and Glycopyrolate was done. Patients were divided randomly in two groups: Group N- Nitroglycerine ointment $2 \%, 2.5 \mathrm{~cm}$ topically applied on forhead, 10 min .prior to induction. Group E- Esmolol $0.6 \mathrm{mg} / \mathrm{kg}$ IV $2 \mathrm{~min}$. prior to induction. Both group were induced and laryngoscopy and tracheal intubation was done within 20 sec. Heart rate, blood pressure and mean arterial pressure was recorded before induction and at 1,2,3,5,10 and 15 min after laryngoscopy and intubation. Statistical analysis was done using students ' $\mathrm{t}$ ' test and was considered significant if $\mathrm{p}<0.05$. Results: Patients in esmolol group remained haemodynamically more stable than nitroglycerine group. Conclusion: In our study it is concluded that Esmolol is more effective than Nitroglycerine in attenuating the haemodynamic response to laryngoscopy and intubation.

Keywords: Nitroglycerine, Esmolol, Laryngoscopy, intubation.

Corresponding Author: Dr Ravneet Kaur, Department of Anaesthesia JNU Medical College Jaipur.

Received: November 2019

Accepted: November 2019

\section{Introduction}

Laryngoscopy and tracheal intubation provoke stress response manifesting as hypertension and tachycardia. These transitory changes are maximum at 1 minute following intubation and lasts for 5-10 minutes. ${ }^{[1]}$ These changes are more significant and pose serious challenges in patients with cardiovascular diseases like hypertension, coronary artery disease, aneurysmal vascular disease. ${ }^{[2]}$

There is urgent need for drug which can attenuate the cardiovascular response to the laryngoscopy and intubation. Various drugs eg $\beta$ blockers, calcium channel blockers, Nitroglycerine, opioids, $\alpha 2$ adrenergic agonists, inhalational agents, Lidocaine etc have been used to suppress this response. $^{[3]}$

Esmolol, cardioselective competitive $\beta$ antagonist has a rapid onset of action and short half life of 9 minutes. ${ }^{[4]}$ It prevents rise in heart rate, stroke volume and cardiac output.

Nitroglycerine exerts its action by combining with receptors situated in the wall of blood vessels and causes generalized vasodilatation resulting in suppression of pressor response. Nitroglycerine ointment $2 \%$ in doses of $12.5 \mathrm{mg}$ to $40 \mathrm{mg}$ has duration of action of 3-4 hours.

The present study is undertaken to determine the efficacy of
Esmolol $0.6 \mathrm{mg} / \mathrm{kg}$ IV and $2 \%$ Nitroglycerine $2.5 \mathrm{~cm}$ topically in attenuating the sympathetic responses to laryngoscopy and tracheal intubation.

\section{Aims and Objectives}

To compare the effects of transdermal nitroglycerine and intravenous Esmolol on hemodynamic response to Laryngoscopy and intubation in terms of :

- Heart rate

- Systolic and diastolic blood pressure

- Mean arterial pressure.

To compare the effectiveness of Esmolol $0.6 \mathrm{mg} / \mathrm{kg} \mathrm{IV}$ over Nitroglycerine $2.5 \mathrm{~cm}$ topically or vice versa.

\section{Subjects and Methods}

A randomized double blind study was conducted in department of anaesthesia, JNUIMSRC. 50 Patients of age group 22 and 55 years belonging to ASA grade I and II posted for surgery under general anaesthesia were randomly divided into two groups of 25 each.

Patients were assessed preoperatively and informed consent obtained. In the operation theatre, intravenous line was started with Ringer lactate. Premedication with Midazolam $0.07 \mathrm{mg} / \mathrm{kg}$ and Glycopyrrolate $0.01 \mathrm{mg} / \mathrm{kg}$ was done. 
Patients were divided randomly in two groups:

$>$ Group N- received Nitroglycerine ointment $2 \%$ a column of $2.5 \mathrm{~cm}$ taken on a graduated paper strip and topically applied on forhead, $10 \mathrm{~min}$ prior to induction.

$>$ Group E- received Esmolol $0.6 \mathrm{mg} / \mathrm{kg}$ IV 2 min. prior to induction.

After pre-oxygenation, both groups were induced with $2.5 \%$ Thiopentone sodium $5 \mathrm{mg} / \mathrm{kg}$ and inj Succinyl -choline $2 \mathrm{mg} / \mathrm{kg}$. Laryngoscopy and tracheal intubation was done within $20 \mathrm{sec}$ after fasciculations due to Succinyl- choline subsided. Heart rate, blood pressure and mean arterial pressure were recorded before induction and at 1,2,3,5,10 and $15 \mathrm{~min}$ after laryngoscopy and intubation.

On completion of surgery,patients were reversed with glycopyrrolate and neostigmine.

Statistical analysis was done using students ' $\mathrm{t}$ ' test and was considered significant if $\mathrm{p}<0.05$.

\section{Results}

[Table 1] shows distribution of patients according to age. Maximum patients were in fourth and fifth decade.
[Table 2] shows mean age and mean weight with standard deviations. Both the groups are comparable with regards to age and weight as difference is statistically insignificant.

[Table 4] shows highly significant changes in pulse rate uptil 3 minutes after laryngoscopy and intubation. Esmolol group shows less changes than nitroglycerine group.

[Table 5] shows raised systolic blood pressure in both groups. Significant rise in blood pressure persisted upto 5 minutes after laryngoscopy and intubation in nitroglycerine group but it reached to basal vale at 3 minutes in Esmolol group.

Table 1: Distribution of patients according to age.

\begin{tabular}{|l|l|c|c|c|c|}
\hline S. & \multirow{2}{*}{ Groups } & \multicolumn{4}{|c|}{ Age in years } \\
\cline { 3 - 6 } No & & $\mathbf{2 1 - 3 0}$ & $\mathbf{3 1 - 4 0}$ & $\mathbf{4 1 - 5 0}$ & $\mathbf{5 1 - 6 0}$ \\
\hline 1 & Nitroglycerine & 2 & 14 & 8 & 1 \\
\hline 2 & Esmolol & 4 & 10 & 10 & 1 \\
\hline
\end{tabular}

Table 2: Mean age and mean weight.

\begin{tabular}{|l|l|l|}
\hline Groups & Age In Years & Weight Kg \\
\hline Nitroglycerine & $39.68 \pm 6.14$ & $50.36 \pm 6.46$ \\
\hline Esmolol & $39.76 \pm 8.3$ & $49.16 \pm 5.03$ \\
\hline
\end{tabular}

Table 3: Pulse Rate per Min. Mean \pm Standard Deviation

Table 3: Pulse Rate per Min. Mean \pm Standard Deviation
\begin{tabular}{|l|l|l|l|}
\hline S. No. & 0bservation Time & Nitroglycerine & Esmolol \\
\hline 1 & After premedication & $95.84 \pm 13.58$ & $91.64 \pm 11.95$ \\
\hline 2 & Before laryngoscopy and intubation & $115.72 \pm 11.19$ & $106 \pm 12.85$ \\
\hline 3 & Just after laryngoscopy and intubation & $128.52 \pm 15.27$ & $110.8 \pm 15.64$ \\
\hline 4 & After laryngoscopy and intubation at & & \\
\hline & $1 \mathrm{~min}$ & $121.32 \pm 14.69$ & $107.32 \pm 16.74$ \\
\hline & $2 \mathrm{~min}$ & $115.88 \pm 13.47$ & $109 \pm 11.01$ \\
\hline & $3 \mathrm{~min}$ & $110 \pm 15.47$ & $105.68 \pm 11.4$ \\
\hline & $5 \mathrm{~min}$ & $105.88 \pm 16.53$ & $103.44 \pm 14.47$ \\
\hline & $10 \mathrm{~min}$ & $104.56 \pm 14.7$ & $98.84 \pm 14.11$ \\
\hline & $15 \mathrm{~min}$ & $101.88 \pm 13.76$ & $94.52 \pm 12.88$ \\
\hline
\end{tabular}

Table 4: Mean Changes In Pulse Rate

\begin{tabular}{|l|l|l|l|l|l|}
\hline S No. & Observation Time & Nitroglycerine & Esmolol & \multicolumn{2}{l|}{} \\
\cline { 3 - 6 } & & Mean Change & P Value & Mean Change & P VALUE \\
\hline 1 & Before laryngoscopy and intubation & $19.8 \pm 11.75$ & $<.001$ & $14.36 \pm 14.8$ & $<.001$ \\
\hline 2 & Just after laryngoscopy and intubation & $32.68 \pm 14.34$ & $<.001$ & $19.16 \pm 17.1$ & \\
\hline 3 & After laryngoscopy and intubation at & & & & $<.001$ \\
\hline & $1 \mathrm{~min}$ & $25.48 \pm 14.23$ & $<.001$ & $15.68 \pm 15.82$ & $<.001$ \\
\hline & $2 \mathrm{~min}$ & $20.04 \pm 12.6$ & $<.001$ & $17.36 \pm 15.16$ & $<.001$ \\
\hline & $3 \mathrm{~min}$ & $14.16 \pm 13.7$ & $<.001$ & $14.04 \pm 15.2$ & $<.001$ \\
\hline & $5 \mathrm{~min}$ & $10.0 \pm 15.16$ & $<.01$ & $11.8 \pm 17.5$ & $<.01$ \\
\hline & $10 \mathrm{~min}$ & $8.72 \pm 14.3$ & $<.01$ & $9.28 \pm 10.8$ & $<.05$ \\
\hline & $15 \mathrm{~min}$ & $6.0 \pm 14$ & $>.05$ & $3.36 \pm 14.1$ & $>.05$ \\
\hline
\end{tabular}

Table 5: Mean Systolic Blood Pressure Mmhg Mean \pm Standard Deviation

\begin{tabular}{|l|l|l|l|}
\hline S. No. & observation Time & Nitroglycerine \\
\hline 1 & After premedication & $135.2 \pm 10.4$ & Esmolol \\
\hline 2 & Before laryngoscopy and intubation & $133 \pm 13.35$ & $132.96 \pm 9.6$ \\
\hline 3 & Just after laryngoscopy and intubation & $167.2 \pm 16.46$ & \\
\hline 4 & After laryngoscopy and intubation at & & $131.92 \pm 15.43$ \\
\hline & $1 \mathrm{~min}$ & $165.84 \pm 17.6$ & $164.56 \pm 16.97$ \\
\hline & $2 \mathrm{~min}$ & $154.56 \pm 20.04$ & $153.6 \pm 13.96$ \\
\hline & $3 \mathrm{~min}$ & $148.48 \pm 15.93$ & $143.28 \pm 15.93$ \\
\hline & $5 \mathrm{~min}$ & $137.52 \pm 14.18$ \\
\hline & $10 \mathrm{~min}$ & $131.2 \pm 12.44$ \\
\hline
\end{tabular}

Table 6: Mean Changes and p Value of Systolic Blood Pressure (compared to basal value)

\begin{tabular}{|l|l|l|l|l|l|}
\hline S No. & Observation Time & Nitroglycerine & Esmolol \\
\cline { 3 - 6 } & & Mean Change & P Value & Mean Change & P VALUE \\
\hline 1 & Before laryngoscopy and intubation & $-2.16 \pm 11.3$ & $<.001$ & $14.36 \pm 14.8$ & $<.001$ \\
\hline
\end{tabular}


Saxcena et al: Attenuating the Hocmadynamic Respanse ta Laryngascopy and Intulation

\begin{tabular}{|c|c|c|c|c|c|}
\hline 2 & Just after laryngoscopy and intubation & $30.8 \pm 13.4$ & $<.001$ & $19.16 \pm 17.1$ & $<.001$ \\
\hline 3 & After laryngoscopy and intubation at & & & & \\
\hline & $1 \mathrm{~min}$ & $30.6 \pm 14.3$ & $<.001$ & $20.6 \pm 17.9$ & $<.001$ \\
\hline & $2 \mathrm{~min}$ & $19.36 \pm 15.8$ & $<.001$ & $8.5 \pm 17.9$ & $<.05$ \\
\hline & $3 \min$ & $13.3 \pm 13.1$ & $<.001$ & $5.2 \pm 15.6$ & $>.05$ \\
\hline & $5 \min$ & $8.08 \pm 11.9$ & $<.01$ & $4.4 \pm 15.7$ & $>.05$ \\
\hline & $10 \mathrm{~min}$ & $2.32 \pm 12.8$ & $>.05$ & $1.68 \pm 14.55$ & $>.05$ \\
\hline & $15 \mathrm{~min}$ & $-4 \pm 11.13$ & $>.05$ & $-1.36 \pm 13.16$ & $>.05$ \\
\hline
\end{tabular}

Table 7: Diastolic Blood Pressure MMHG (Mean \pm Standard Deviation)

\begin{tabular}{|l|l|l|l|}
\hline S. No. & 0bservation Time & Nitroglycerine & Esmolol \\
\hline 1 & Before laryngoscopy and intubation & $85.92 \pm 5.81$ & $87.12 \pm 4.36$ \\
\hline 2 & Just after laryngoscopy and intubation & $120.56 \pm 9.2$ & $118.08 \pm 14.33$ \\
\hline 3 & After laryngoscopy and intubation at & & \\
\hline & $1 \mathrm{~min}$ & $118.24 \pm 9.56$ & $112.56 \pm 11.79$ \\
\hline & $2 \mathrm{~min}$ & $110.32 \pm 10.30$ & $104 \pm 11.2$ \\
\hline & $3 \mathrm{~min}$ & $107.68 \pm 10.62$ & $101.6 \pm 9.38$ \\
\hline & $5 \mathrm{~min}$ & $103.6 \pm 11.61$ & $100.4 \pm 8.8$ \\
\hline & $10 \mathrm{~min}$ & $98.4 \pm 10.66$ & $97.2 \pm 8.45$ \\
\hline & $15 \mathrm{~min}$ & $90.4 \pm 9.08$ & $93.44 \pm 8.11$ \\
\hline
\end{tabular}

Table 8 MEAN CHANGES AND p VALUE OF DIASTOLIC BLOOD PRESSURE (compared to basal value)

\begin{tabular}{|l|l|l|l|l|l|}
\hline S No. & Observation Time & Nitroglycerine & \multicolumn{2}{l|}{ Esmolol } \\
\cline { 3 - 6 } & & Mean Change & P Value & Mean Change & P VALUE \\
\hline 1 & Before laryngoscopy and intubation & $7.44 \pm 9.75$ & $<.001$ & $14.36 \pm 14.8$ & $<.001$ \\
\hline 2 & Just after laryngoscopy and intubation & $34.64 \pm 9.5$ & $<.001$ & $19.16 \pm 17.1$ & \\
\hline 3 & After laryngoscopy and intubation at & & & & \\
\hline \\
\hline & $1 \mathrm{~min}$ & $32.32 \pm 10.17$ & $<.001$ & $25.44 \pm 12.03$ & \\
\hline & $2 \mathrm{~min}$ & $24.4 \pm 10.29$ & $<.001$ & $16.88 \pm 10.65$ & $<.001$ \\
\hline & $3 \mathrm{~min}$ & $21.76 \pm 10.1$ & $<.001$ & $14.48 \pm 8.89$ & $<.001$ \\
\hline & $5 \mathrm{~min}$ & $17.60 \pm 11.63$ & $<.001$ & $13.8 \pm 8.79$ & $<.001$ \\
\hline & $10 \mathrm{~min}$ & $12.48 \pm 10.65$ & $<.001$ & $10.08 \pm 9.77$ & $<.001$ \\
\hline & $15 \mathrm{~min}$ & $4.48 \pm 9.51$ & $<.05$ & $6.32 \pm 8.73$ & $<.01$ \\
\hline
\end{tabular}



Figure 1: Mean Change in Pulse Rate

Mean changes in pulse rate was less in esmolol group as compared to nitroglycerine group. So pulse rate was more stable in esmolol group.

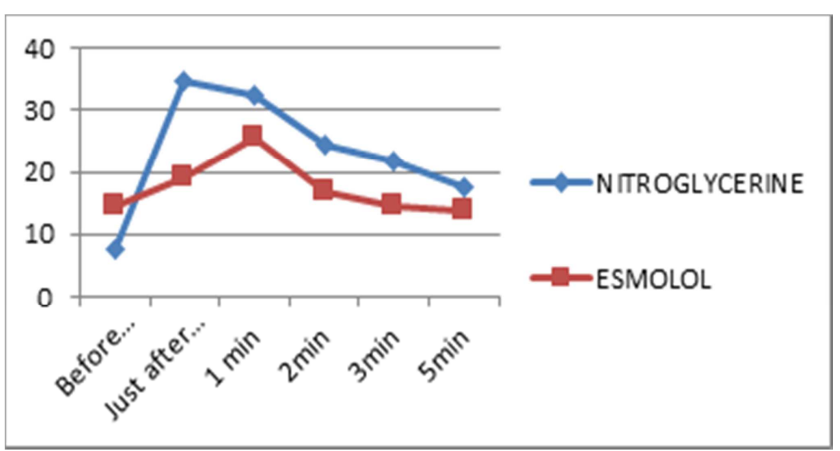

Figure 2: Mean Change in Systolic Blood Pressure

As shown in the graph, systolic blood pressure reached baseline value in 3 minutes in Esmolol group. Hence patient remained haemodynamically more stable in Esmolol group as compared to nitroglycerine group.

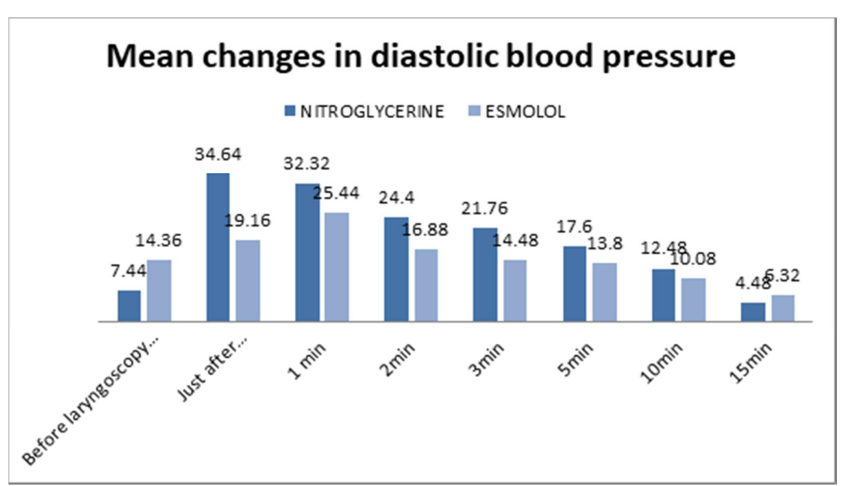

Figure 3: Mean Change in Diastolic Blood Pressure

[Table 6] shows mean changes in systolic blood pressure after laryngoscopy and intubation.

[Table 7] shows raised diastolic blood pressure in both groups. [Table 8] shows rise in diastolic blood pressure was statistically significant till 15 minutes after laryngoscopy and intubation in both the groups.

\section{Discussion}

Intubation is associated with a cardiovascular response in the form of elevated blood pressure, heart rate and occasional dysrhythmias so the anesthesiologist and pharmacologist are in search of the drug to hamper these responses. 1 This study 
was undertaken to compare Esmolol and Nitroglycerine with different mechanism of action to reduce haemodynamic response to laryngoscopy and intubation.

Nitroglycerine produces generalized vasodilatation including coronary artery dilation, which leads to decrease in blood pressure, lowers the myocardial oxygen demand on one hand and on the other side myocardial oxygen supply is increased by coronary artery dilatation. It is being used intravenously, topically, intranasally and sublingually.

Esmolol is a new ultra-short acting beta blocker with selective $\beta 1$ blocking activity. Beta blockers in therapeutic doses has no marked effect on normal heart rate but are effective in the presence of increased sympathetic activity. In our study there are statistically no significant differences between both groups regarding age and body weight.

Significant increase in heart rate was observed in both groups after laryngoscopy and intubation, but it was less in Esmolol group as compared to nitroglycerine group because $\beta-1$ receptors were blocked in Esmolol group. This is in concordance with study done by Ugur et al, ${ }^{[5]}$ who compred the efficacy of Esmolol $1.5 \mathrm{mg} / \mathrm{kg}$, Fentanyl $1 \mu \mathrm{gm} / \mathrm{kg}$, Lignocaine $1.5 \mathrm{mg} / \mathrm{kg}$ and control. This study showed significant decrease in H.R. in Esmolol group as compared to control group, immediately after induction and $1 \mathrm{~min}$ after intubation.

Attenuation of heart rate in Esmolol group was also observed by Singh $\mathrm{H}$ et $\mathrm{al}^{[6]}{ }^{[6}$ when Esmolol, Lignocaine, Nitroglycerine and control group were compared for attenuation of haemodynamic response.

In our study highly significant increase in systolic blood pressure was observed just after laryngoscopy and intubation compared to basal values with a rise of $30.8 \mathrm{mmHg}(22.58 \%)$ and $31.6 \mathrm{mmHg}(23.76 \%)$ in Nitroglycerine and Esmolol groups respectively. Increased systolic blood pressure after laryngoscopy and intubation remained significant upto 5 minutes in Nitroglycerine group while it was significant only for $1 \mathrm{~min}$ in Esmolol group.

These results are in agreement with Helfman SM et al7 and Sahare KK et al, ${ }^{[8]}$ where significant rise in SBP after laryngoscopy and intubation was noted with Esmolol and topical Nitroglycerine treated patients respectively.
Rise in diastolic blood pressure was $34.64 \mathrm{mmHg}(40.3 \%)$ and 30.96(35.5) in Nitroglycerine and Esmolol group respectively immediately after laryngoscopy and intubation. This is in concordance with Sahare KK et al, ${ }^{[8]}$ where topical Nitroglycerine was used in attenuating pressor response. Singh et ${ }^{16},{ }^{[6]}$ also concluded in its study that Esmolol boluses has overall higher level of efficacy than Nitroglycerine.

\section{Conclusion}

In our study it is concluded that Esmolol is more effective than Nitroglycerine in attenuating the haemodynamic response to laryngoscopy and intubation.

\section{References}

1. Varma TARS, Aparanji K, Uma R. A Comparative Study of efficacy of esmolol and fentanyl for attenuation of intubation response during laryngoscopy. J of Evolution of Med and Dent Sci 2015;4(39):6778-86.

2. Singh SP, Quadir A, Malhotra P. Comparison of esmolol and labetolol, in low doses, for attenuation of sympathomimetic response to laryngoscopy and intubation. Saudi J Anaesth. 2010 Sep-Dec;4(3):163168.

3. Firoozbakhsh F, Mohammadi FH, Safari S, Khashayar P. The effect of intravenous nitroglycerine on blood pressure during intubation. Middle East J Anesthesiol 2008;19:859-67.

4. Menkhaus PG, Reves JG, Alvis MS, Kirklin JK. Attenuation of heart rate response to intubation by a new $\beta$ adrenergic blocking drug, Esmolol. Anaesthesiology. 1984;61:A20.

5. Ugur B, Ogurlu M, Gezer E, Nuri Aydin O et al. Effects of esmolol, lidocaine and fentanyl on haemadynamic responses to endotracheal intubation: a comparative study. Clin Drug Investig 2007;27:269-77.

6. Singh H, Vichitvejpaisal P, Gaines GY, Whiote PF. Comparaive effects of Lignocaine, Esmolol and Nitroglycerine in modifying the haemodynamic response to laryngoscopy and intubation. J Clin Anaesth. $1995 \mathrm{Feb} ; 7(1): 5-8$.

7. Helfman SM, Martin IG, Delisser EA, Herrington CA. Which drug prevents tachycardia and hypertension associated with tracheal intubation: Lidocaine, Fentanyl or Esmolol. Anesth Analg.1991;72:486.

8. Sahare KK, Neema MM, Lad SR. Nifedipine and topical nitroglycerine in attenuation of cardiovascular response to laryngoscopy and tracheal intubation. Ind J Anaesth 1997;41:113-117.

Copyright: ( ) the author(s), publisher. Academia Anesthesiologica International is an Official Publication of "Society for Health Care \& Research Development". It is an open-access article distributed under the terms of the Creative Commons Attribution Non-Commercial License, which permits unrestricted non-commercial use, distribution, and reproduction in any medium, provided the original work is properly cited.

How to cite this article: Saxena AK, Kaur R, Mathur BL, Verma AP. A Comparative Evaluation of Nitroglycerine and Esmolol in Attenuating the Haemodynamic Response to Laryngoscopy and Intubation. Acad. Anesthesiol. Int. 2019;4(2):332-35.

DOI: dx.doi.org/10.21276/aan.2019.4.2.75

Source of Support: Nil, Conflict of Interest: None declared. 